Please do not remove this page

RMIT

UNIVERSITY

\title{
Mechanical properties of thermally-treated and recycled glass fibres
}

Feih, Stefanie; Boiocchi, E; Mathys, G; Mathys, Z; Gibson, A.; Mouritz, Adrian

https://researchrepository.rmit.edu.au/esploro/outputs/9921858099401341/filesAndLinks?institution=61RMIT_INST\&index=null

Feih, S., Boiocchi, E., Mathys, G., Mathys, Z., Gibson, A., \& Mouritz, A. (2011). Mechanical properties of thermally-treated and recycled glass fibres. Composites Part B-Engineering, 42(3), 350-358.

https://doi.org/10.1016/j.compositesb.2010.12.020

Document Version: Accepted Manuscript

Published Version: https://doi.org/10.1016/j.compositesb.2010.12.020

Repository homepage: https://researchrepository.rmit.edu.au

(C) 2011 Elsevier Ltd.

Downloaded On 2023/04/26 22:58:34 +1000

Please do not remove this page 
Thank you for downloading this document from the RMIT Research Repository.

The RMIT Research Repository is an open access database showcasing the research outputs of RMIT University researchers.

RMIT Research Repository: http://researchbank.rmit.edu.au/

\section{Citation:}

Feih, S, Boiocchi, E, Mathys, G, Mathys, Z, Gibson, A and Adrian, M 2011, 'Mechanical properties of thermally-treated and recycled glass fibres', Composites Part B-Engineering, vol. 42, no. 3, pp. 350-358.

See this record in the RMIT Research Repository at:

http://researchbank.rmit.edu.au/view/rmit:12372

Version: Accepted Manuscript

Copyright Statement: (c) 2011 Elsevier Ltd.

Link to Published Version:

http://dx.doi.org/10.1016/j.compositesb.2010.12.020 
NOTICE: this is the author's version of a work that was accepted for publication in Composites Part B: Engineering. Changes resulting from the publishing process, such as peer review, editing, corrections, structural formatting, and other quality control mechanisms may not be reflected in this document. Changes may have been made to this work since it was submitted for publication. A definitive version was subsequently published in Composites Part B: Engineering, vol. 42, issue 3, April 2011. http://dx.doi.org/10.1016/j.compositesb.2010.12.020

\title{
MECHANICAL PROPERTIES OF THERMALLY-TREATED AND RECYCLED GLASS FIBRES
}

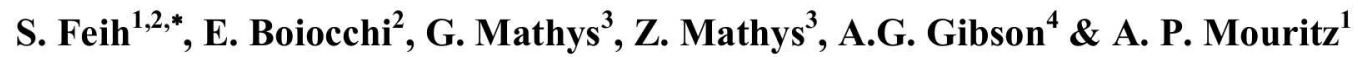 \\ 1. School of Aerospace, Mechanical \& Manufacturing Engineering, \\ Royal Melbourne Institute of Technology, Melbourne, Victoria, 3001, Australia \\ 2. Cooperative Research Centre for Advanced Composite Structures Ltd (CRC-ACS), \\ Fishermans Bend, Victoria, 3207, Australia \\ 3. Defence Science \& Technology Organisation, Melbourne, Victoria, 3001, Australia \\ 4. Centre for Composite Materials Engineering, Stephenson Building, \\ University of Newcastle-upon-Tyne, United Kingdom
}

Composites Part B

*e-mail: stefanie.feih@rmit.edu.au

Tel.: +61399256193

Fax: +61399256108 


\section{ABSTRACT}

This paper investigates the effects of temperature, heating time and atmosphere on the tensile modulus and strength of thermally-treated E-glass fibres. The heating conditions that were investigated are identical to those used in thermal recycling of waste polymer matrix composite materials, and therefore this study determines the effects of the recycling process conditions on the properties of reclaimed fibreglass. The loss in fibre strength is dependent on the temperature and time of the thermal process, and large strength loss occurs under the heating conditions used for high temperature incineration of polymer composites. A phenomenological model is presented for the residual fibre strength for the temperatures and heating time of the thermal recycling process. The reduction in fibre strength is dependent on the thermal recycling atmosphere under low temperature or short heating time conditions, but at high temperatures the strength loss is the same, regardless of furnace atmosphere (ambient air, dry air or inert gas). Quantitative fractographic analysis of the fibres shows that fracture for all heat treatments is caused by surface flaws. The strength loss is most probably due to structural relaxation during thermal annealing and a secondary effect of adsorbed surface water attacking the glass by thermally-activated stress-corrosion. It is shown that large reductions in fibre strength due to thermal recycling are not recovered during composite manufacture, therefore resulting in composite materials with significantly lower strength. The reduced strength of the composite matches the reduced fibre strength following thermal recycling.

Keywords: A: Glass fibres; B: Fracture; B: Mechanical Properties, E: Recycling 


\section{INTRODUCTION}

The disposal of composite products in an environmentally friendly way is one of the most important challenges facing the industry and community. It is projected that the total global production of composite materials will exceed 10.3 MT by 2015, which will occupy a volume of over 60 million cubic meters. Glass fibre-thermoset matrix materials account for about $90 \%$ of all the composites currently produced, and these are difficult and expensive to recycle. The current cost of recycling glass-thermoset composites is not competitive against the cost of using new material. Furthermore, the mechanical properties of recycled glass fibres are lower than the original material, and are usually too low to find use in structural composite products requiring high strength. For these reasons, land-fill is the most common way of disposal for waste composite material. However, this poses an environmental problem because of the extremely large volume of material that must be buried annually. Furthermore, glass fibres are durable and do not break-down easily in soil. Increasingly, governments and local councils are limiting or completely banning the disposal of composites by land fill-in. For example, the European Union recently set limits on the amount of composites placed in land-fill and Germany has imposed a complete ban.

As disposal of composites into land fill-in becomes more difficult, the industry is being forced to recycle greater quantities of material. Various methods are used to recycle composites, and they are generally classified as regrind, chemical or thermal processes [1-8]. The most common process is thermal recycling by pyrolysis inside a rotary kiln or fluidized bed. The process basically involves incinerating the waste composite at high temperature (typically $400-550^{\circ} \mathrm{C}$ ) in the absence of air to decompose the polymer matrix into oil/wax, char and gas. After the polymer has been removed, the fibres are heated in air to oxidize residual char and remove surface contamination. The fibres are then recovered for reuse. However their mechanical strength is reduced by the high temperature needed to decompose the matrix $[9,10]$. The 
strength of glass fibre decreases rapidly with increasing temperature above $\sim 400^{\circ} \mathrm{C}$, and the typical temperatures used to incinerate thermoset matrix composites result in strength loss of $80-95 \%$ [11]. Such a large strength reduction means that reclaimed glass fibre is not suitable for reuse in structural composites. To date there have been no published studies that have systematically studied the effects of reprocessing parameters of the thermal recycling process (e.g. temperature, time, furnace atmosphere) on the residual properties of reclaimed E-glass fibres.

This paper reports the effects of thermal recycling processing conditions on the tensile strength of commercial E-glass fibres. The strength loss was determined following treatments at different temperatures $\left(150-650^{\circ} \mathrm{C}\right)$, heating times (up to two hours) and furnace atmospheres (ambient air, dry air and inert gas). This covers and exceeds the range of conditions used in commercial thermal recycling processes. A phenomenological model is presented for the effects of temperature and heating time on the residual strength of reclaimed E-glass fibres. The paper also examines the mechanisms responsible for the reduction in fibre strength during recycling. It is expected that information presented here could be used to identify the optimum thermal recycling conditions to minimize strength loss of reclaimed E-glass fibres.

In this study the strength of E-glass fibres was determined in the absence of a polymer matrix, to avoid the possible influence of fibre-matrix interactions. The thermal process is shown to be the main reason for the property loss. Glass fibres (as opposed to glass reinforced composites) were exposed to thermal conditions representative of thermal recycling. This allowed a controlled study to isolate the influence of the thermal recycling process on the fibre properties. 


\section{MATERIALS \& EXPERIMENTAL METHODS}

\subsection{Fibres}

The effects of temperature, heating time and atmosphere were investigated using E-glass fibres. The fibres were coated with a silane-based sizing agent (111A) that is chemically compatible with many thermoset resins. The fibres were supplied in 300 tex bundles with an average fibre diameter of $12 \mu \mathrm{m}$. Fibre bundles were heat-treated in a custom-designed bench furnace with controllable temperature and atmosphere that replicates the incinerators used for thermal recycling. The fibres were heated to different temperatures between 150 and $650^{\circ} \mathrm{C}$ for times up to two hours in various atmospheres. This heating range covers the pyrolysis temperatures used in conventional incineration processes (above $450^{\circ} \mathrm{C}$ ) and new processes involving lower pyrolysis temperatures. The maximum temperature of $650^{\circ} \mathrm{C}$ is sufficiently close to the glass transition temperature of E-glass $\left(680^{\circ} \mathrm{C}\right)$ to allow for full annealing of all internal stresses introduced during the manufacturing process when heat-treated for the period of two hours [12].

The effect of the furnace atmosphere was investigated by heating the fibres in high purity nitrogen (also containing less than $25 \mathrm{ppm}$ water), ambient air (with an ambient temperature relative humidity of about $50 \%$ ) or dry air (with a water content under $25 \mathrm{ppm}$ ). The nitrogen atmosphere is used to replicate the initial stage of the thermal recycling of composites when heating is performed under inert conditions. The ambient air replicates the second stage when the glass fibres are heat-treated in air to remove residual char and contamination from the surface. The dry air atmosphere was used to understand the influence of air-borne water on the strength loss of glass fibres at high temperature, although this type of air is not used in commercial thermal recycling processes. After heating, the fibres were cooled inside the furnace environment, and then tensile tested to measure the residual modulus and strength. 
The tensile properties of single fibres extracted from fibre bundles were measured at room temperature using a $2.5 \mathrm{~N}$ Instron 4501 operated at a cross-head displacement rate of 0.5 $\mathrm{mm} / \mathrm{min}$. An individual fibre was mounted on a thin cardboard support frame containing a 20 mm long rectangular cut-out which defined the specimen gauge length, according to ASTM C 1577-03. Prior to testing, the fibre diameter was measured using a LS101 Mitutoyo laser micrometer to within an accuracy of $3 \%$ (or $0.4 \mu \mathrm{m}$ ). The fibres were tested under monotonically increasing load to failure to determine the elastic modulus and tensile strength. A minimum of 30 fibres were tested for each heat-treatment condition. After testing, the fracture surfaces of the fibres were examined using scanning electron microscopy (LEO 1530VP-21-32).

Weibull strength parameters for the single fibres were derived based on the two-parameter Weibull strength distribution [13]:

$$
P_{f}=1-\exp \left(-\left(\frac{\sigma}{\sigma_{0}}\right)^{m}\right)
$$

where $P_{\mathrm{f}}$ is the failure probability and $\sigma_{0}$ and $m$ are the Weibull parameters of the distribution. The two parameters were calculated according to the maximum likelihood method. 95\% confidence intervals for both parameters were determined as outlined in the ASTM standard C 1239-00.

Tensile testing of fibre bundles was performed at $20^{\circ} \mathrm{C}$ using a $10 \mathrm{kN}$ Instron 4501 machine at an extension rate of $2 \mathrm{~mm} / \mathrm{min}$. The ends of the fibre bundle were wrapped around circular rollers so that the applied stress was introduced into the specimen via friction, which ensured failure occurred in the gauge section which was $150 \mathrm{~mm}$ long. At least five fibre bundles were 
tested for each heat-treatment condition. The tensile breaking force was measured, which can be related to the maximum bundle strength $\sigma_{\max , f b}$ using the expression

$$
\sigma_{\max , f b}=\frac{F_{\max } \rho_{f}}{W_{f b}}
$$

where $W_{f b}$ is the weight per unit length of the bundle and $\rho_{f}$ is the fibre density. The subscript $f_{b}$ signifies fibre bundle.

\subsection{Composites}

The tensile properties of composite materials containing original and heat-treated glass fibres were measured to determine the strength loss with reclaimed fibres. A plain weave E-glass fabric (2400 tex bundles, 111A sizing agent) in the as-received condition and following heattreatment at various temperatures from $150^{\circ} \mathrm{C}$ to $650^{\circ} \mathrm{C}$ for 2 hours in ambient air was used for the composite specimens. The heat-treated fabric represents reclaimed fibres following thermal recycling. This fabric was not resized or cleaned following the heat-treatment process. Seven ply layers of as-received or heat-treated glass fabric were stacked in a [0/90] pattern, then impregnated with a low-temperature cure vinyl ester resin (Derakane 411-350, Ashland Composite Polymers) using the vacuum bag resin infusion process. After infusion, the composite was cured at room temperature with a post-cure of $80^{\circ} \mathrm{C}$ for 2 hours. The fibre volume content of the composites containing original or heat-treated fabric was approximately $55 \%$.

Tensile testing was performed on dog-bone shaped specimens of the composite containing original or heat-treated fabric according to ASTM D638. The specimens were $57 \mathrm{~mm}$ long, 13 
$\mathrm{mm}$ wide (gauge section), and $4.2 \mathrm{~mm}$ thick. The specimens were loaded in the $0^{\circ}$ fibre direction to failure at a constant rate of $0.5 \mathrm{~mm} / \mathrm{min}$ using a $50 \mathrm{kN}$ Instron 5569 machine.

\section{RESULTS AND DISCUSSION}

\subsection{Effect of Temperature \& Time on Recycled Fibre Modulus}

The Young's modulus remained unchanged $(\mathrm{E}=74 \mathrm{GPa} \pm 5 \%)$ for all heat-treatment conditions, which implies that the molecular structure of the fibres is not significantly altered. It has been reported by Otto [14] that heat treatment increases the fibre density due to compaction of the open silica network structure. Glass fibre density is lower than that of bulk glass as a result of the high rate of cooling during manufacture. The density increase has been shown to result in an increase in modulus from $75 \mathrm{GPa}$ (room temperature) to $86 \mathrm{GPa}$ at elevated temperature of $600^{\circ} \mathrm{C}$ [14]. While no increase to the Young's modulus of the glass fibres was found due to heat treatment, the results indicate that thermal recycling will not degrade the stiffness of reclaimed glass fibres.

\subsection{Effect of Temperature \& Time on Recycled Fibre Strength}

Figure 1 shows the effects of temperature and heating time on the residual tensile strength of the single glass fibres and fibre bundles. The strengths of the heat-treated fibres and bundles in Figure 1 were normalised to their average original strength at room temperature, which is 2284 MPa for the single fibres and $1085 \mathrm{MPa}$ for the bundles. The bundle strength was over $50 \%$ lower because of friction effects between the fibres, uneven straining of fibres under tension, and the longer specimen gauge length (20 $\mathrm{mm}$ for single fibres and $150 \mathrm{~mm}$ for bundles). Similar differences between the strengths of single fibres and bundles in the as-received condition have been reported by R'Mili and Reynaud [15].

Figure 1 shows that the fibre and bundle strengths drop rapidly over the temperature range of $250-550^{\circ} \mathrm{C}$. The strength initially decreases rapidly with time, and then reaches a minimum 
steady-state value which is determined by the temperature. The time taken to reach steady-state strength shortens with increasing temperature. While the fibres and bundles show similar trends, the percentage reduction in steady-state strength for the fibre bundles is about $30 \%$ higher than for the single fibre at the same temperature. Several studies report large reductions in fibre strength following high temperature treatment of glass filaments $[9,10]$ or thermal recycling of fibreglass composites [8,11]. Kennerly et al. [11], for example, reported a 95\% loss in fibre strength following recycling of a fibreglass laminate at $650^{\circ} \mathrm{C}$. This percentage reduction in strength is similar to the strength loss measured for the glass fibre bundles heated at $650^{\circ} \mathrm{C}$, thus showing that the heat-treatment applied in this study can mimic the results of the thermal recycling process on composites. Based on this comparison, property reduction due to resinfibre interaction is classified as a secondary effect.

A phenomenological model relating residual strength to temperature and heating time can be developed using the data in Figure 1. Such a model is useful for predicting the fibre strength following thermal recycling at any temperature and time without the need to perform experimental residual strength tests. The curves in Figure 1 follow a profile that can be described mathematically by a tanh function relating fibre strength $\left(\sigma_{f}\right)$ to temperature $(T)$ and heating time $(t)$ :

$\sigma_{f}(t, T)=\sigma_{f(0)}-\sigma_{\text {loss }}(T) \tanh \left|k_{f}(T) t\right|$

where $\sigma_{f(0)}$ is the original fibre strength, $\sigma_{\text {loss }}(T)$ describes the strength loss, and $k_{f}(T)$ describes the rate of strength loss. The strength loss, $\sigma_{\text {loss }}(T)$, is determined by curve-fitting the function:

$$
\sigma_{\text {loss }}(T)=\left(\frac{\sigma_{f(0)}-\sigma_{f(a)}}{2}\right)\left(1+\tanh \left[p_{f}\left(T-T_{50 \%}\right)\right]\right)
$$


with $T_{50 \%}$ and $p_{f}$ being curve fitting constants. $\sigma_{f(a)}$ is the remaining strength of the glass fibre following heat treatment close to the glass transition temperature of E-glass. $T_{50 \%}$ is the temperature at which the fibre loses $50 \%$ of the original strength for long exposure times. The developed phenomenological model predicts zero strength loss at low temperatures. The model furthermore predicts a remaining strength $\left(\sigma_{f(a)}\right)$ at high temperatures and long exposure times.

Temperature exposure close to the glass transition temperature of $680^{\circ} \mathrm{C}$ has previously been shown by Lund and Yue to approach reduced steady-state strength [12]. The remaining fibre strength is still significantly higher than the strength of bulk glass. The value for the remaining strength of the E-glass fibre in this study $\left(\sigma_{\mathrm{f}(\mathrm{a})}\right)$ is in good agreement with values measured in a range of $600-800 \mathrm{MPa}[12]$.

The rate of strength loss, $k_{f}(T)$, is given by:

$k_{f}(T)=k_{1} e^{k_{2} T}$

where $k_{1}$ and $k_{2}$ are constants.

The curves in Figure 1 show the predicted reductions in strength for the glass fibres and bundles using the phenomenological model. There is good agreement with the experimental data, and the model has practical use because it can be used to calculate the effects of temperature and heating time of the thermal recycling process on the residual fibre strength as well as recycled composite strength (as will be discussed later). The fitted values according to Eq. (4) and Eq. (5) are given in Table 1 . The results in Table 1 show that the remaining strength at high temperature $\left(\sigma_{f(a)}\right)$ is significantly lower for fibre bundles than the remaining strength following heat 
treatment of the single fibres. The activation energy for strength loss, as indicated by the value $k_{2}$, is significantly higher for fibre bundles. The difference in results is attributed to a second strength loss mechanism of friction damage within the bundle, which is absent for single fibres. Organic sizing on the fibres is removed by thermal decomposition during heat treatment above $\sim 350^{\circ} \mathrm{C}$. The size provides lubrication between fibres during bundle testing, so its removal will result in greater frictional forces. These forces are believed to create fine-scale damage on the fibre surface which lowers the bundle strength.

\subsection{Effect of Atmosphere on Recycled Fibre Strength}

The residual strength of single fibres following heating in ambient air ( 50\% relative humidity), dry air (containing less than 25 ppm water) and inert gas (nitrogen with under 25 ppm water) was used to determine the influence of the recycling furnace atmosphere on the fibre strength loss. As mentioned, thermal recycling of waste composite is initially performed in an inert atmosphere to decompose the matrix by pyrolysis, followed by heat treatment in air to remove char and other contaminants from the fibre surface. Therefore, the separate effects of inert (nitrogen) and ambient air on fibre strength were investigated. The effect of dry air was also studied to establish whether atmospheric moisture, which is generally seen as the most important factor promoting zero-stress ageing and stress-corrosion of silicate glasses [16], has any influence on fibre strength during recycling.

Figure 2 shows Weibull strength distribution plots for the fibre following heating at $450^{\circ} \mathrm{C}$ for 30 minutes in the different atmospheres. The temperature of $450^{\circ} \mathrm{C}$ was selected because it is within the range of temperatures $\left(400-550^{\circ} \mathrm{C}\right)$ used for thermal recycling. The fibre strength was reduced by the heat-treatment regardless of whether it was performed in air or nitrogen. However, the strength loss was less in nitrogen compared with ambient or dry air, which produce identical strength distributions. When heating is performed at higher temperatures or longer times the atmosphere has no significant influence on the loss in fibre strength. For 
example, Figure 3 and Figure 4 show strength distribution plots for the fibre after heating in ambient air or nitrogen at $450^{\circ} \mathrm{C}$ for two hours or $550^{\circ} \mathrm{C}$ for 30 minutes, respectively. The average residual strength and the distribution of strength values were similar whether heating occurred in air or nitrogen. The fibre strength appears a little lower after heating in nitrogen at $550^{\circ} \mathrm{C}$, but this difference is not regarded as statistically significant.

These trends in strength loss correlate with the decomposition of the organic/organosilane size on the glass fibres. The mass loss of the fibre when heated in air or nitrogen was determined with thermogravimetric analysis (TGA) using a Netzsch TG 209 F1 instrument. The percentage mass loss-temperature curves measured using TGA are presented in Figure 5. The mass loss of the fibres increases with temperature due to decomposition and volatilization of the organic size, which occurs over the range $250-500^{\circ} \mathrm{C}$. This is the decomposition temperature range for epoxybased sizings [17]. The total mass loss due to decomposition is small due to the thin layer of size on the fibres. Glass fibres themselves show no significant mass loss under these heating conditions (apart from possibly small losses in adsorbed water). TGA reveals that the mass loss rate and percentage mass loss is slightly less when heated in nitrogen, indicating a slower decomposition rate for the size in the absence of oxygen. The volatile gas products evolved from the fibre when heated in air or nitrogen was analyzed with Fourier Transform Infrared Spectrometry (FTIR). The FTIR spectrometer (Bruker Tensor 27) was equipped with a DTGS detector and a low-volume gas cell $(8.7 \mathrm{ml})$. Figure 6 shows the evolution of water over the decomposition temperature range of the organic size. The source of water is most probably three-fold [18-20]: firstly, water is strongly adsorbed by hydrogen bonding to the glass surface; secondly, during decomposition of the silane-based sizing, chain scission of oxygen-containing silanol groups degrade to siloxane groups and water; and lastly water is evolved from the decomposition of epoxy resin and polyether species present in the size. The FTIR analysis reveals that the water concentration is higher when decomposition of the organic size occurs in the presence of air. 
The composition of the fibre surface before and after heating in air and nitrogen was investigated using X-ray photoelectron spectroscopy (XPS). The XPS was performed using a field emission Auger microscope (VG310F) operated with a non-monochromated $\mathrm{Al}_{\mathrm{K} \alpha} \mathrm{X}$-ray source at $20 \mathrm{~mA}$ and $15 \mathrm{kV}$. The major peaks of carbon $(\mathrm{C})$, oxygen $(\mathrm{O})$, silicon $(\mathrm{Si})$, aluminium (Al), calcium (Ca) and sodium (Na) were analysed for each fibre sample. XPS revealed that the surface chemistry of the fibres heated in nitrogen and air were different. The fibre heated in nitrogen was coated with a carbon-rich material, almost certainly carboneous char formed as a solid by-product of the decomposition reaction of the size. In comparison, the fibre heated in air at the same temperature and time had a very low carbon signal, and it appears the char was absent due to oxidation processes.

Based on the TGA, FTIR and XPS analysis, it appears that the slower rate in strength loss of the glass fibre when heated in inert gas at $450^{\circ} \mathrm{C}$ (Figure 2) correlates with less decomposition of the organic size, lower water yield, and higher char content on the surface. The atmosphere therefore seems to influence the rate and the activation energy for strength loss. The influence of the decomposition of the organic size and presence of molecular water is therefore classified as a strength-reduction effect acting on the fibre surface, which influences the strength loss rate. At higher temperatures or longer heating times the residual strength of the fibre is not significantly affected by the atmosphere. Fractography results are discussed in the next section for further investigation of the strength loss mechanism.

\subsection{Fracture of Recycled Fibres}

Fracture surfaces of single fibre specimens before and after heat-treatment were examined using scanning electron microscopy to identify the failure mechanism. Scanning electron images representative of the fracture surfaces for different environments are presented in Figure 7. It 
should be noted that the shown mirror sizes and thus strength values in the figure are not indicative of the average strength, but identify the typical failure features. A large spread in mirror sizes is obtained for the same heat treatment time and temperature due to the low Weibull modulus of glass fibres following temperature exposure. In all cases, failure originated from the fibre surface as established by the fracture mirror location. Failure was never found to initiate within the fibre, which implies that the reduction in fibre strength is caused by a damage mechanism that is only active at the surface.

All the fracture surfaces, regardless of temperature, time or atmosphere, were characterized by the three regions - mirror, mist and hackle - which are shown schematically in Figure 8. These regions are known to be caused by changes in the crack growth rate. The mirror zone is the smooth, featureless region surrounding the original surface flaw. As the crack accelerates it becomes increasingly unstable, which creates a dimpled surface known as the mist. The crack eventually branches out and produces the rough hackle region [21, 22].

The mirror, mist and hackle regions were present in every investigated fibre fracture regardless of heat treatment conditions, which suggests that the failure process is not affected by temperature, time or atmosphere-induced changes to the bulk or surface properties of the glass. The only significant difference between the fracture surfaces for fibres heated under different conditions was the size of the mirror zone. It was observed that the size of the mirror zone increased with decreasing fibre strength. Shand [21] and Mecholsky et al. [22] report that the tensile strength of glass is related to the size of the mirror zone according to:

$$
\sigma_{f}=A_{m}\left(d_{m}\right)^{-1 / 2}
$$


where $d_{m}$ is the mirror depth and $A_{\mathrm{m}}$ is the so-called mirror constant which is generally related to the fracture toughness of the material. Figure 9 shows a plot of the reciprocal square root of the mirror depth against strength for the single fibres heated under different conditions. The average value for the mirror constant based on the data in Figure 9 is $1.7 \mathrm{MPa} \cdot \mathrm{m}^{0.5}$. The value is in agreement with other published values for glass fibres and bulk glass (1.8 MPa.m ${ }^{0.5}$ [23], 2.5 MPa.m $\left.{ }^{0.5}[24]\right)$. The data plotted in Figure 9 for the three atmospheric conditions fall on the same linear curve, which therefore indicates that the mirror constant is not sensitive to the thermal history of the fibre. This finding is supported by the fact that the mirror constant for bulk glass and optical fibres is similar to the heat-treated glass fibres.

\subsection{Discussion of Strength Loss Mechanism}

The exact mechanism for strength loss is still a subject of further research. The thermal history of glass fibres has been used to explain the superior strength of glass fibres compared to bulk glass. Both the drawing stress and the frozen-in structure of hyper-quenched E-glass fibres have been found to be strongly associated with the high fibre strength $[12,25]$, but detailed measurements relating strength loss to the time-dependent relaxation at elevated temperature are missing.

During manufacture, an open glass pore structure is frozen-in under rapid cooling as validated by the increasing density of glass fibres and compaction during annealing [14]. Anisotropy due to deformation of the silica network structure and the resultant changes to the Si-O-Si and other interatomic bonding angles also occurs due to the tensile drawing stress; especially for the Si-OSi angle as confirmed by birefringence measurements [26]. Elevated temperature treatment has been shown to lead to structural relaxation of internal deformation states. It has furthermore been shown that the two mechanisms of structural relaxation are decoupled, with optical birefringence relaxation due to anisotropy occurring at shorter time and lower temperatures when compared to enthalpy relaxation. Optical relaxation was therefore shown to be related to 
local structural arrangements, whereas enthalpy relaxation seems to be dominated by the relaxation of the large-range silica melt network $[25,27]$. The level of structural relaxation depends on the heat-treatment temperature, hence leading to a temperature-dependent steadystate value for the strength of annealed fibres.

In the current study, fracture was found to always occur from the surface. This finding is consistent with a mechanism in which strength loss is assisted by structural surface relaxation, which is known to occur faster at the surface than in the bulk of the fibre. Structural relaxation occurs due to increased temperature, but is further promoted by the presence of molecular water due to diffusion [28]. Lanford et al. [29] examined the diffusion of water into the near-surface region of soda-lime glass using nuclear resonance profiling of hydrogen. It was found that water was present to a depth of 500-600 $\mathrm{nm}$ [29], which is close to the maximum flaw size estimated for the heat-treated fibres. In related work, for high temperatures of $650^{\circ} \mathrm{C}$, Agarwal et al. [30] also found that the maximum depth that water penetrates below the glass surface does not increase with time after the near-surface region has reached the solubility limit for water, and that the water uptake occurs more rapidly for this temperature than compared to $250^{\circ} \mathrm{C}$. The resulting water-rich surface layer is expected to result in a changed stress state of the glass fibre surface due to ion exchange processes [31]. Tomozawa and Hepburn [28] postulate that structural relaxation results in embrittlement of the glass structure and thereby reduced strength. Another possible surface-controlled strength loss mechanism involves deepening of pre-existing surface flaws by water attacking the region of the silica network at the crack tip. This mechanism reduces the fibre strength, even in the absence of an externally applied tensile stress [32].

Linear-elastic fracture mechanics can be used to estimate the critical flaw size in the glass fibres following the different heat-treatment conditions. The flaw length $(c)$ is proportional to the measured fibre strength $\left(\sigma_{f, a v}\right)$ via the well-known relationship: 
$c=\frac{1}{\pi}\left(\frac{\sigma_{f, a v} Y(c, R)}{K_{I c}}\right)^{2}$

$K_{I c}$ is the mode I fracture toughness $\left(0.76 \mathrm{MPa} . \mathrm{m}^{0.5}\right.$ for silicate glasses [33]), which is assumed not to change by heat-treatment based on the mirror constant. $Y(c, R)$ is a geometric stress concentration factor dependent on the ratio of fibre radius $(R)$ and flaw length. $Y(c, R)$ equals $2 / \pi$ for a semicircular flaw, provided the flaw is significantly smaller than the fibre radius.

Using Eq. (7) and assuming that no subcritical flaw growth occurs during the tensile test prior to catastrophic failure, the flaw size is predicted to increase from $90 \mathrm{~nm}$ (as-received) to flaw sizes around $800 \mathrm{~nm}\left(T=650^{\circ} \mathrm{C}\right)$, which is significant when compared to the average fibre diameter of $d=12 \mu \mathrm{m}$. Figures $2-4$ indicate a mostly parallel strength shift with only a small decrease of the $m$-value from 7-8 for as-received fibres to values of around $m=5$ for the heat-treated fibres. A parallel shift in strength distribution was also found by Lund and Yue [12]. Assuming that flaws are growing due to heat treatment, this indicates that all tested fibres contain large flaws. Flaws of this size were not observed on the fibre surface using SEM, although this does not provide conclusive evidence that they are absent. Flaws may be hard to detect on the surface of unstressed fibres due to the cracks being closed.

The rate of strength loss due to heat treatment was calculated based on the single fibre strength data (presented in Figure 1a), and plotted against the inverse of absolute temperature in Figure 10. The rate of strength loss is evaluated for short time periods, where strength loss is approximately linear with heating time. The rate of strength loss increases with temperature and exhibits an Arrhenius-type relationship with an activation energy of $Q=64 \mathrm{~kJ} / \mathrm{mol}$. The activation energies for anisotropy relaxation and enthalpy relaxation for E-glass are quoted at 
$25 \mathrm{~kJ} / \mathrm{mol}$ and $400 \mathrm{~kJ} / \mathrm{mol}$, respectively [27]. Lanford et al. [29] measured the activation energy for water diffusion in glass to be $78 \mathrm{~kJ} / \mathrm{mol}$. A similar value was also reported by Charles [16] for the corrosion process of glass in water vapour up to $250^{\circ} \mathrm{C}$. The activation energy for moisture diffusion in glass is thus similar to the activation energy for flaw growth during heat treatment. For future work, this value needs to be related to activation energies for water diffusion and structural surface and bulk relaxation for commercial E-glass fibres to shed further light on the mechanism responsible for strength loss.

\subsection{Tensile Properties of Composites Containing Heat-Treated Fibreglass}

The results presented on glass fibre heated under conditions representative of thermal recycling cause a large loss in strength. As mentioned, the incineration of composite materials is performed at temperatures above $450^{\circ} \mathrm{C}$, and the results indicate that the loss in strength of single fibres and fibre bundles exceeds $40 \%$ and $80 \%$, respectively. To assess the impact of this strength loss on composite materials containing recycled fibres, the tensile properties of glass/vinyl ester laminates containing original or heat-treated glass fabric were determined. The laminates are identical in every respect (e.g. ply lay-up, thickness, fibre volume content) except that one material contains original fibres and the other material contains fibres heated under conditions representative of thermal recycling.

The strength reduction of the recycled composites and heat-treated fibres as a function of temperature for two hour exposure is compared in Figure 11. It can be seen that the large loss in fibre strength caused by heat-treatment is not recovered when recycled fibres are used in composite materials. The agreement between normalised fibre and composite strength is good, indicating that the phenomenological model can be used to estimate composite strength following recycling if the heating conditions are known. The predictions through the phenomenological model are indicated in the figure by the dotted line. The elastic modulus of the recycled composites remains unchanged, and this is consistent with the finding that heat- 
treatment does not affect the fibre stiffness (regardless of the temperature, heating time or atmosphere).

\section{CONCLUSIONS}

Thermal recycling of polymer composites will become more common as pressure intensifies to limit the disposal of waste material by land-fill. E-glass fibres were heated under the conditions representative of commercial thermal recycling processing to systematically assess the effects of temperature, heating time and furnace atmosphere on the stiffness and strength of reclaimed material. The elastic modulus of fibre glass is not affected by thermal treatment, and as a result the stiffness of composites containing heat-treated fibres is the same as material containing original fibres. The fibre strength decreases rapidly with increasing temperature above 150$250^{\circ} \mathrm{C}$. Decomposition of the polymer resins commonly used in structural composites (e.g. epoxy, polyester, vinyl ester, phenolic) does not begin until the temperature exceeds $300-400^{\circ} \mathrm{C}$. This suggests that glass fibres begin to lose strength during thermal recycling before matrix pyrolysis has commenced.

At the temperatures used in conventional thermal recycling processes (above $450^{\circ} \mathrm{C}$ ), the strength loss for single fibres and fibre bundles exceeds $40 \%$ and $80 \%$, respectively. This strength loss results in composite materials containing recycled fibres having lower tensile strength properties than composites with original fibres. Tensile tests on single fibres and fibre bundles show that the reduction in strength is dependent on both temperature and heating time. A phenomenological model can be used to calculate the residual strength for any thermal recycling processing condition. The reduction in fibre strength during thermal recycling is attributed to the loss of structural anisotropy during annealing, which reduces the intrinsic strength of the material. As a secondary effect, the rate of strength-loss seems to be influenced 
by the presence of water during heat-treatment. Water is adsorbed to the fibre surface and water can be liberated during decomposition of the organic size.

Recycling of the heated-treated glass fibres shows that the fibre strength is not recovered. The phenomenological model can therefore be applied to estimate the strength of composite materials following recycling.

\section{ACKNOWLEDGMENTS}

The project work was supported by the United States Office of Naval Research (Grant No N00014-08-11253) under the direction of Dr Luise Couchman. The research presented in this paper was performed as the project P2.1.2 of the Cooperative Research Centre for Advanced Composite Structures. The technical assistance of Johan DuPlessis (RMIT University) for XPS, Peter Tkatchyk (RMIT University) for mechanical testing, and Richard Muscat (DSTO) for SEM analysis is gratefully acknowledged.

\section{REFERENCES}

1. Mayes JS. Recycling of fibre-reinforced plastics. JEC Composites Magazine 2005; 42(17):24-26.

2. Green Composites: Polymer Composites and the Environment, In: Baillie C, editor. Cambridge: Woodhead Publishing, 2004.

3. Giulvezan G and Carberry W. Composite recycling and disposal - an environmental R\&D issue. Boeing Environment Technotes 2003; 8:1-4.

4. Henshaw JM, Han WJ and Owens AD. An overview of recycling issues for composite materials. Journal of Thermoplastic Composite Materials 1996; 9(1): 4-20. 
5. Henshaw JM. Recycling and disposal of polymer-matrix composites, in ASM Handbook, Volume 21: Composite. Ohio: American Society of Metals, 2001, 1006-1012.

6. Williams PT. Recycling of automotive composites - the pyrolysis process and its advantages. Materials World 2003; 11:24-26.

7. Pickering SJ. Recycling technologies for thermoset composite materials - current status. Composites: Part A 2006; 37(8):1206 - 1215.

8. Cunliffe AM, Jones N and Williams PT. Pyrolysis of composite plastic waste. Environmental Technology 2003; 24(5):653-663.

9. Thomas WF. An investigation of the factors likely to affect the strength and properties of glass fibres. Physics and Chemistry of Glasses 1960; 1(1):4-18.

10. Cameron NM. The effect of environment and temperature on the strength of E-glass fibres. Part 2: Heating and ageing. Glass technology 1968; 9(5):121-130.

11. Kennerley, JR, Kelly RM, Fenwick NJ, Pickering SJ and Rudd CD. The Characterization and Reuse of Glass Fibres Recycled from Scrap Composites by the Action of a Fluidized Bed Process. Composites Part A 1998; 29(7):839-845.

12. M.D. Lund and Y. Yue, Impact of drawing stress on the tensile strength of oxide glass fibres, Journal of the American Ceramic Society (in print).

13. Khalili A and Kromp K. Statistical properties of Weibull estimators. Journal of Materials Science 1991; 26(24):6741-6752.

14. Otto WH. Compaction effects in glass fibers. Journal of the American Ceramic Society 1961; 44(2): 68-72.

15. R'Mili M and Reynaud P. Evaluation of fiber-strength statistical-distribution by bundle tensile tests. ECCM-11 VaFTeM Workshop Conference Proceedings, Greece, 2004.

16. Charles RJ. The static fatigue of glass. Journal of applied physics 1958; 29(11):1549-1553.

17. Mouritz AP and Gibson AG, editors. Fire Properties of Polymer Composite Materials, Dordrecht: Springer, 2006.

18. The properties of glass surfaces, Editor: L. Holland, Wiley, New York, 1964 
19. Gupta PK. Glass fibers. In: Bunsell AR, editor. Fiber Reinforcements for Composite Materials. New York: Elsevier, 1988.

20. Carman LA and Pantano CG. Water-vapor adsorption on calcium-boroaluminosilicate glass fibers. Journal of non-crystalline solids 1990; 120(1-3), 40-46.

21. Shand EB. Breaking stress of glass determined from dimensions of fracture mirrors. Journal of the American Ceramic Society 1959; 42(10):474-477.

22. Mecholsky JJ, Rice RW, Freiman SW. Prediction of fracture energy and flaw size in glasses from measurements of mirror size. Journal of the American Ceramic Society 1974; 57(10):440-443.

23. Castilone RJ, Glaesemann GS and Hanson TA. Relationship between mirror dimensions and failure stress for optical fibers, In: Matthewson MJ and Kurkjian CR, editors. Optical Fiber and Fiber Component Mechanical Reliability and Testing II Conference Proceedings, SPIE, 2002, p. 11-20

24. Mecholsky JJ, Rice RW and Freiman SW (1974) J Am Ceram Soc 57(10) 440-443

25. Ya M, Deubener J and Yue Y. Enthalpy and anisotropy relaxation of glass fibres, Journal of the American Ceramic Society 2008, 91(3): 745-752

26. Stockhorst H and Brueckner R. Structure sensitive measurements of E-glass fibers. Journal of non-crystalline solids 1982; 49(1-3), 471-484

27. Deubener J, Yue Y, Bornhoeft H, Ya M. Decoupling between birefringence decay, enthalpy relaxation and viscous flow in calcium boroalumosilicate glasses. Chemical Geology 2008; 256: $299-305$.

28. Tomozawa M, Hepburn, R.W. Surface structural relaxation of silica glass: a possible mechanism of structural fatigue. Journal of non-crystalline solids 2004; $345 \& 346$ : 449460.

29. Lanford WA, Davis K, Lamarche P, Laursen T and Groleau R. Hydration of soda-lime glass. Journal of non-crystalline solids 1979; 33(2):249-266. 
30. Agarwal A, Tomozawa M and Lanford WA. Effect of stress on water diffusion in silica glass at various temperatures. Journal of non-crystalline solids 1994; 167(1-2): 139-148.

31. Fett T, Guin JP and Wiederhorn SM. Stresses in ion-exchange layers of soda-lime-silicate glass. Fatigue and Fracture of Engineering Materials and Structures 2005; 28(6):507-514.

32. Gy R. Stress corrosion of silicate glass: A review. Journal of non-crystalline solids 2003; 316(1):1-11.

33. Wiederhorn SM. Fracture surface energy of glass. Journal of the American Ceramic Society 1969; 52(2): 99-105. 
Table 1: Fitting parameters for single fibre and fibre bundle model.

\begin{tabular}{|l|l|l|}
\hline Values & Fitted value bundle & Fitted value single fibre \\
\hline$\sigma_{f(a)}[\mathrm{MPa}]$ & 42.0 & 562.0 \\
\hline$T_{50 \%}\left[{ }^{\circ} \mathrm{C}\right]$ & 347.6 & 403.1 \\
\hline$p_{f}\left[{ }^{\circ} \mathrm{C}^{-1}\right]$ & $5.83 \mathrm{E}-3$ & $6.60 \mathrm{E}-3$ \\
\hline$k_{l}\left[\mathrm{~s}^{-1}\right]$ & $1.81 \mathrm{E}-6$ & $8.63 \mathrm{E}-6$ \\
\hline$k_{2}\left[{ }^{\circ} \mathrm{C}^{-1}\right]$ & $1.45 \mathrm{E}-2$ & $1.17 \mathrm{E}-3$ \\
\hline
\end{tabular}




\section{FIGURE CAPTIONS}

Figure 1: Effects of temperature and heating time on the tensile strength of (a) single fibres $\left(\sigma_{\mathrm{av}, \mathrm{f}}\right.$ $=2248 \mathrm{MPa})$ and $(\mathrm{b})$ fibre bundles $\left(\sigma_{\mathrm{av}, \mathrm{fb}}=1058 \mathrm{MPa}\right)$ after heating in ambient air. The solid lines represent the curve fit using the phenomenological model (Eqs (5) and (6)). The error bars represent (a) 95\% confidence intervals for the strength parameter and (b) the standard deviation of at least five experiments.

Figure 2: Weibull strength distribution plots for single fibres in the original condition and after heating at $450^{\circ} \mathrm{C}$ for 30 minutes in ambient air, dry air or nitrogen. The Weibull distribution parameters $\sigma_{0}$ and $m$ according to Eq. (1) are given.

Figure 3: Weibull strength distribution plots for single fibres in the original condition and after heating at $450^{\circ} \mathrm{C}$ for two hours in ambient air or nitrogen. The Weibull distribution parameters $\sigma_{0}$ and $\mathrm{m}$ according to Eq. (1) are given.

Figure 4: Weibull strength distribution plots for single fibres in the original condition and after heating at $550^{\circ} \mathrm{C}$ for 30 minutes in ambient air or nitrogen. The Weibull distribution parameters $\sigma_{0}$ and $m$ according to Eq. (1) are given.

Figure 5: Mass loss-temperature curves for glass fibre heated in air or nitrogen using TGA performed at a heating rate of $10^{\circ} \mathrm{C} / \mathrm{min}$.

Figure 6: Water evolution-temperature curves for glass fibre heated in air or nitrogen using FTIR performed at a heating rate of $10^{\circ} \mathrm{C} / \mathrm{min}$.

Figure 7: Scanning electron micrographs of the fracture surfaces of fibres heated under different conditions: (a) original without heat treatment $(\sigma=1570 \mathrm{MPa})$, (b) heat-treated in ambient air $(\sigma=370 \mathrm{MPa}),(\mathrm{c})$ heated in dry air $(\sigma=900 \mathrm{MPa})$ and $(\mathrm{d})$ heat-treated in nitrogen $(\sigma=1300 \mathrm{MPa})$. Figure 8: Schematic representation of the fracture surface of the glass fibres in the original condition or any heating at any temperature, time or atmosphere. $d_{\mathrm{m}}$ is the length of the mirror zone. 
Figure 9: Plot of fibre strength vs. mirror depth $\left(d_{\mathrm{m}}^{-1 / 2}\right)$ for single fibre specimens heated at different temperatures, times and atmospheres.

Figure 10: Strength loss rate and activation energy of single glass fibres heated in air. Error bars indicate the $95 \%$ confidence interval in strength loss rate based on the Weibull strength estimators. The variation in strength loss rate diminishes for large strength reductions.

Figure 11: Comparison of normalised tensile strength for single fibres and recycled composites as a function of heat-treatment temperature and two hour exposure time 
Figure 1a

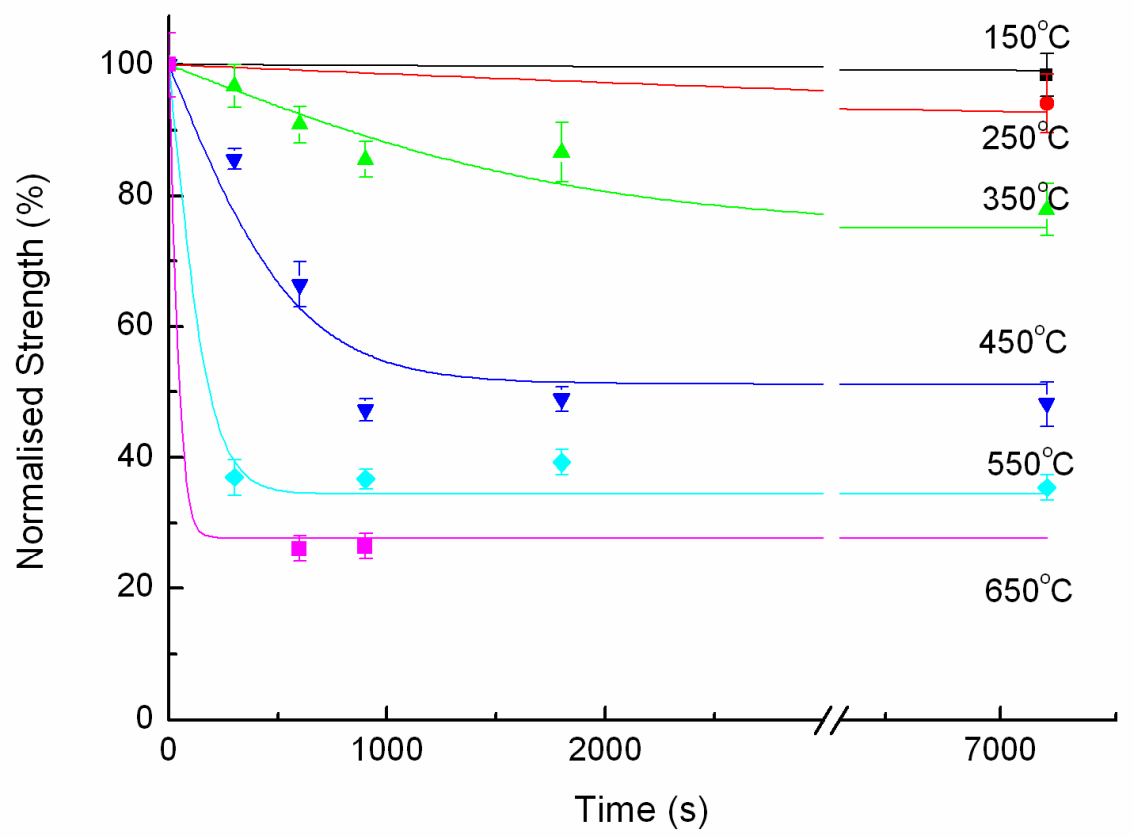

Figure 1b

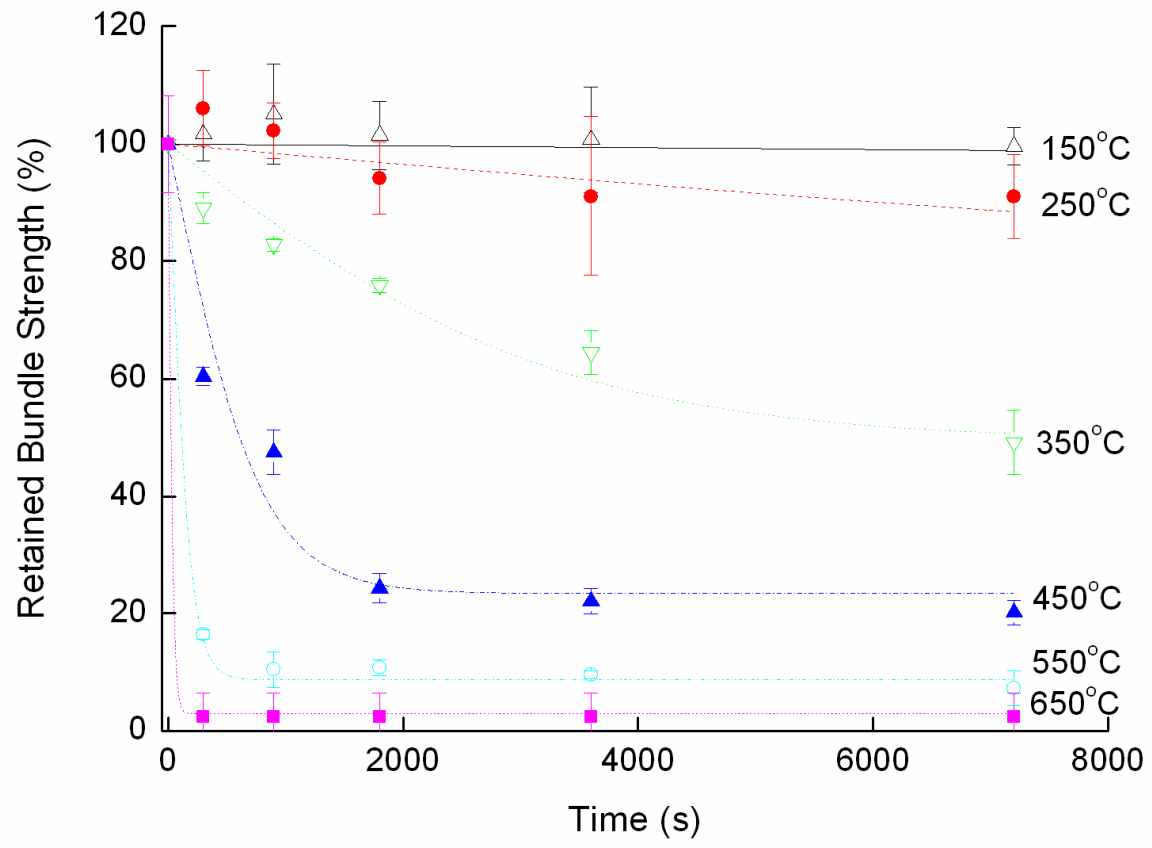


Figure 2

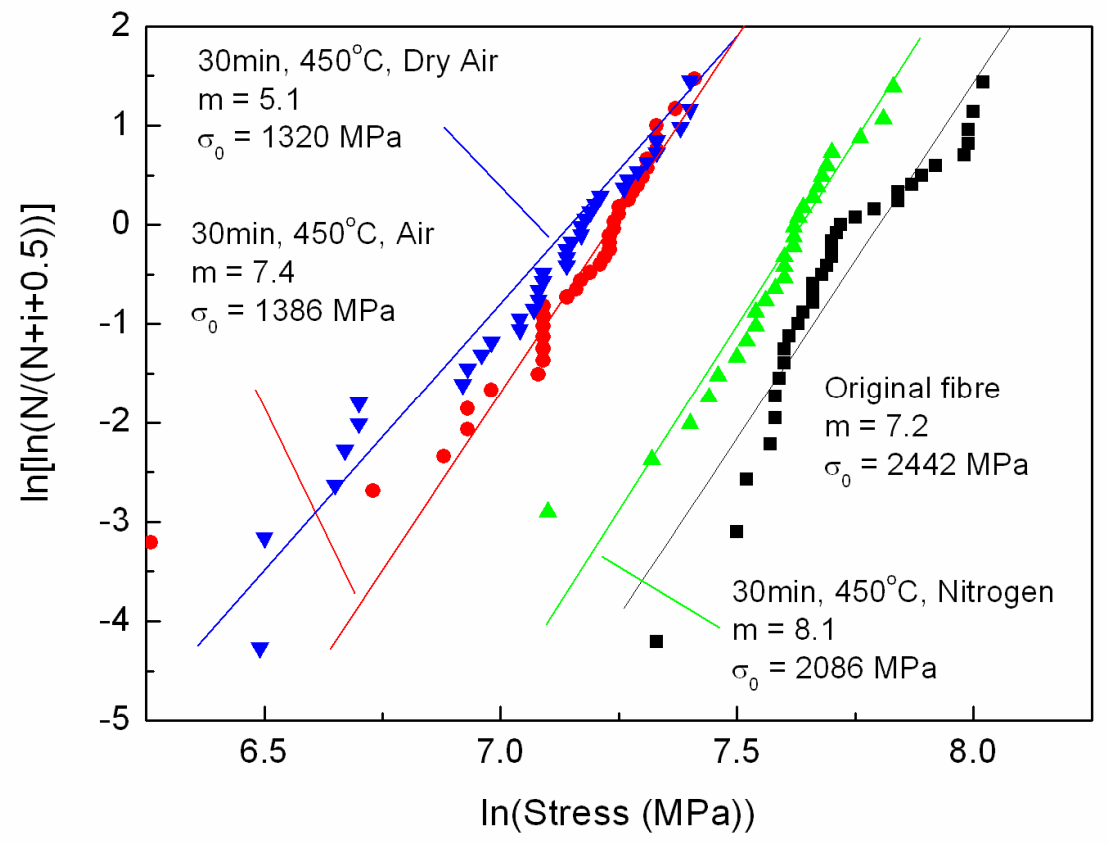


Figure 3

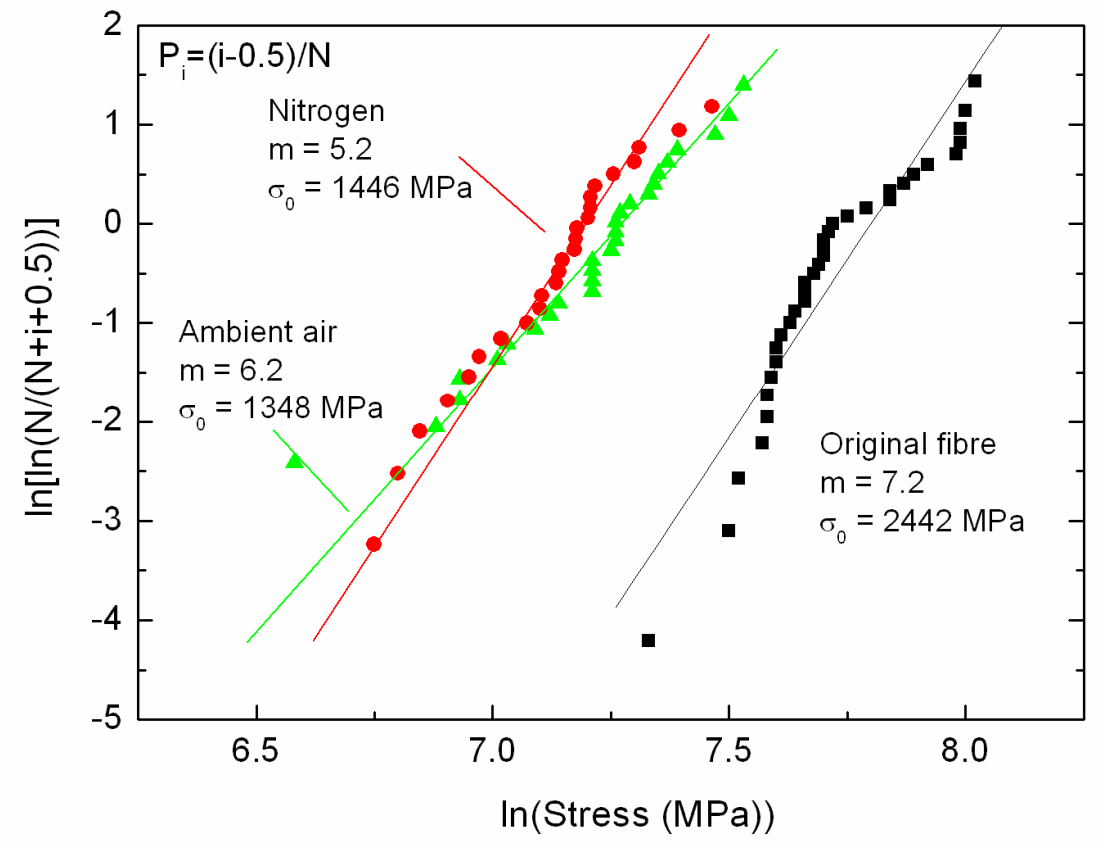


Figure 4

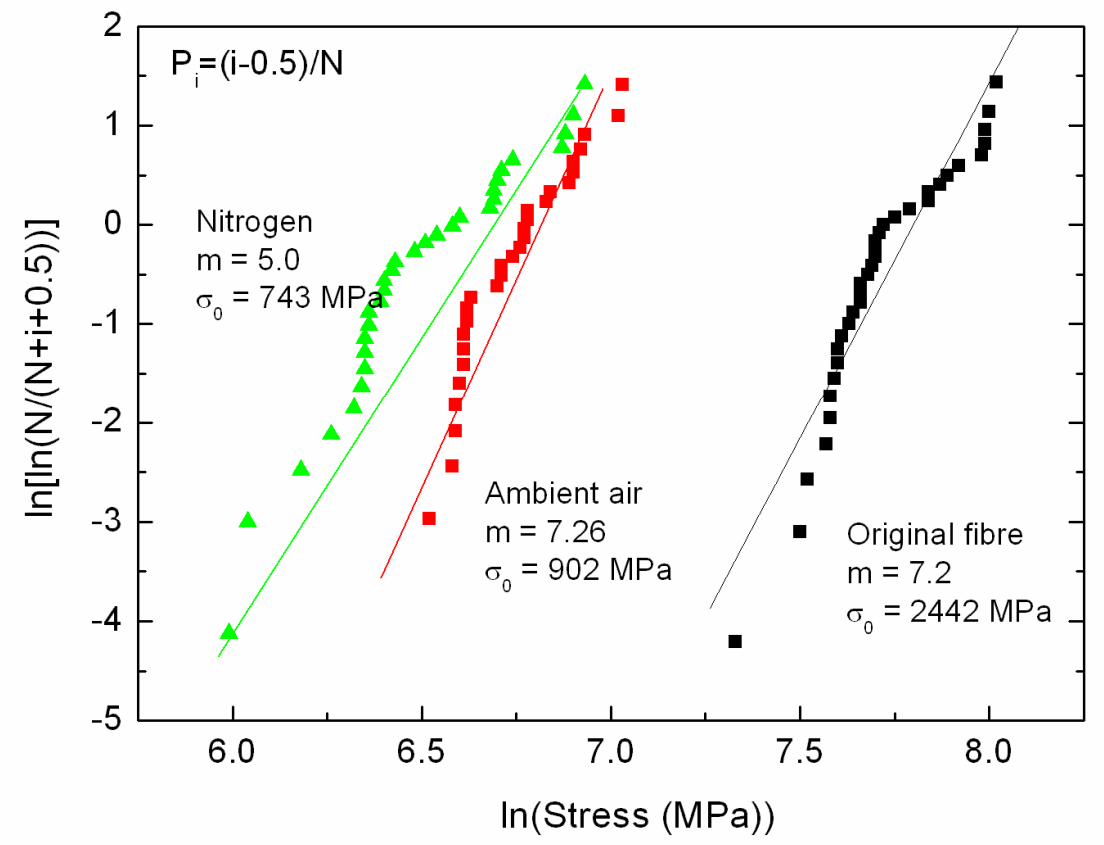


Figure 5

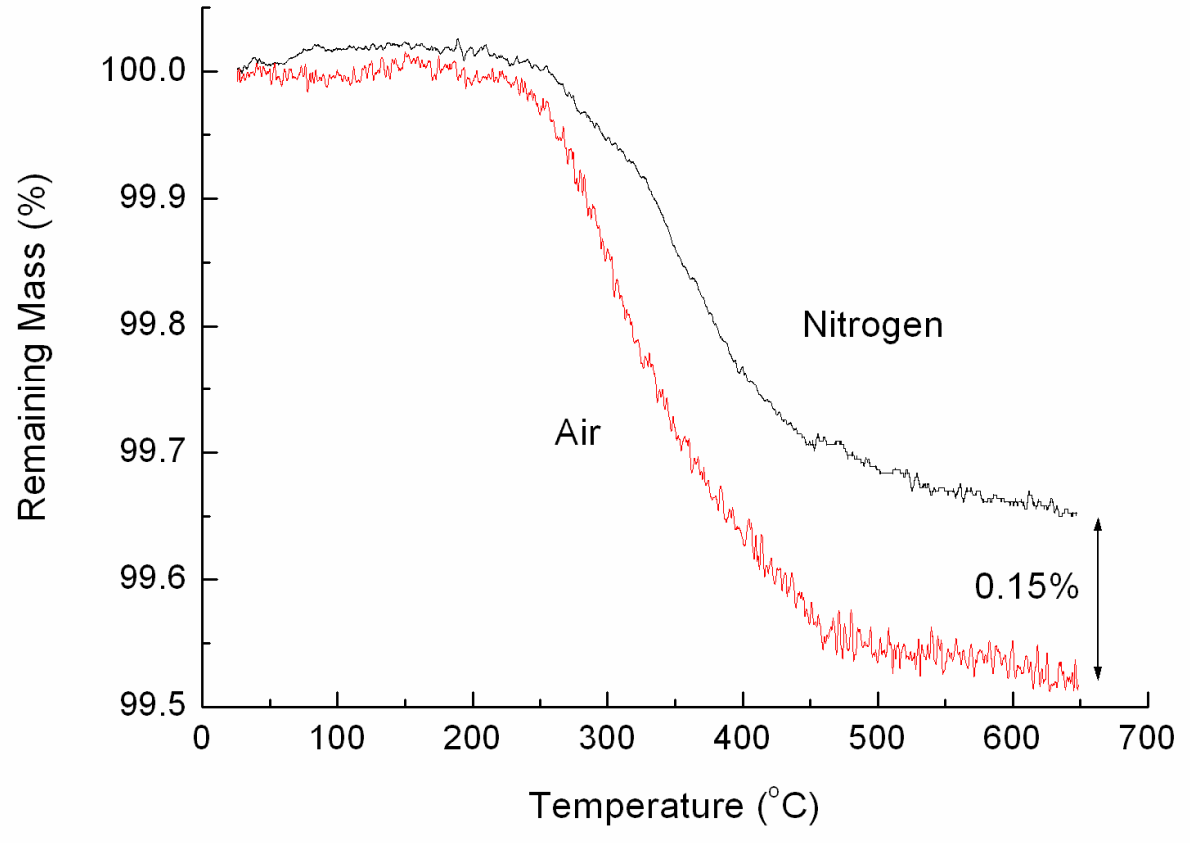


Figure 6

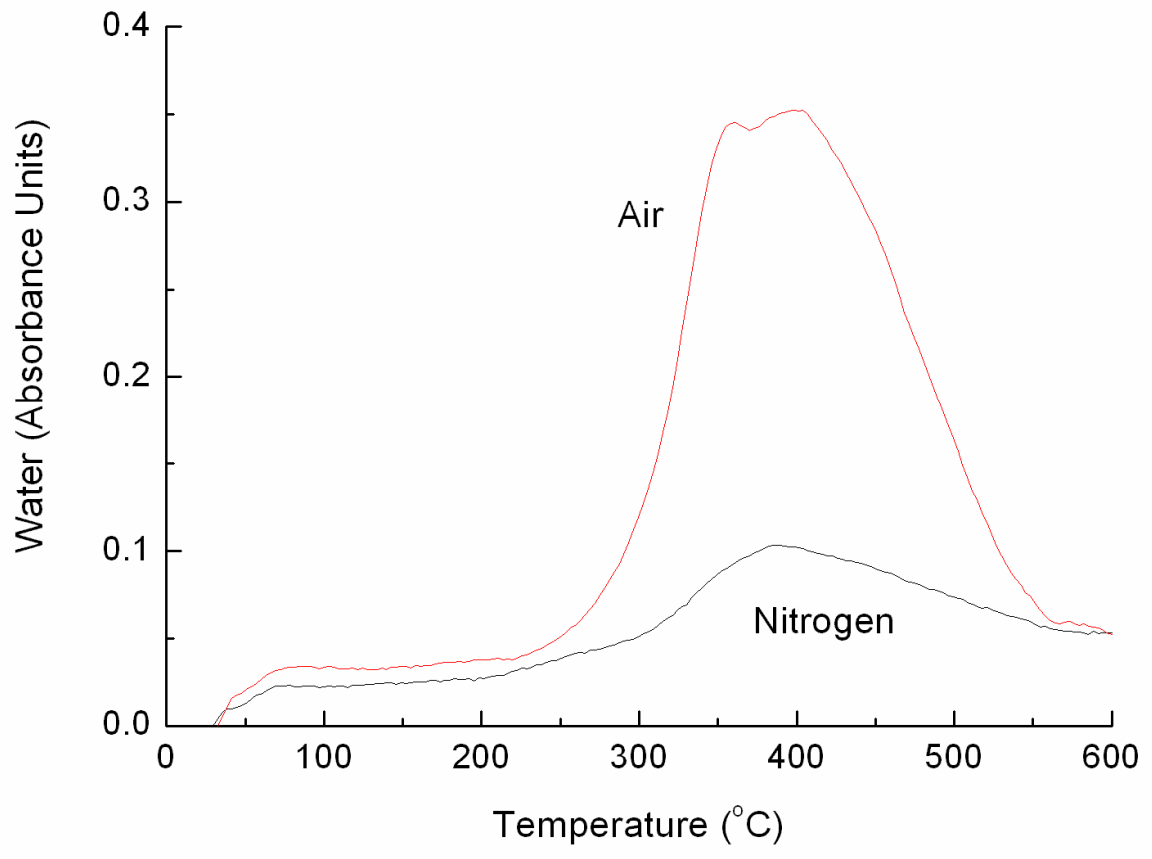


Figure $7 \mathrm{a}$

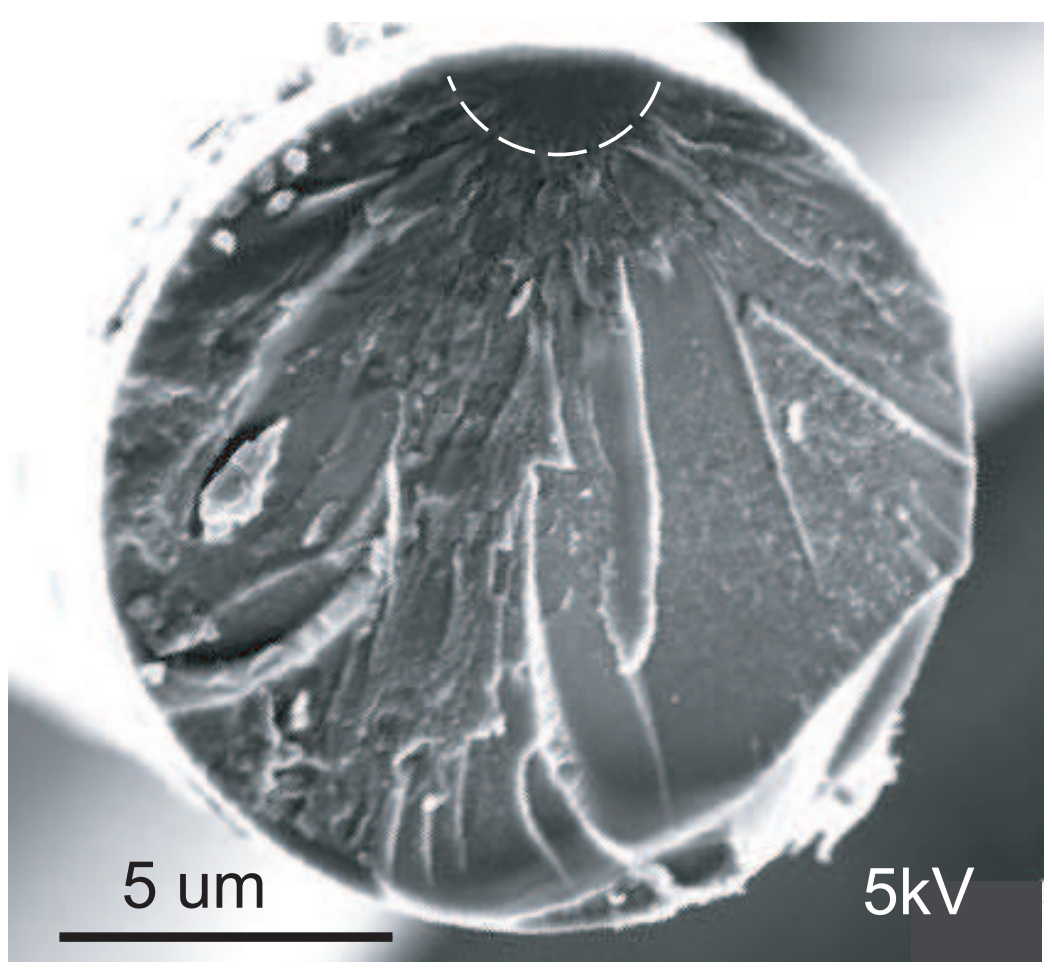

Figure $7 b$

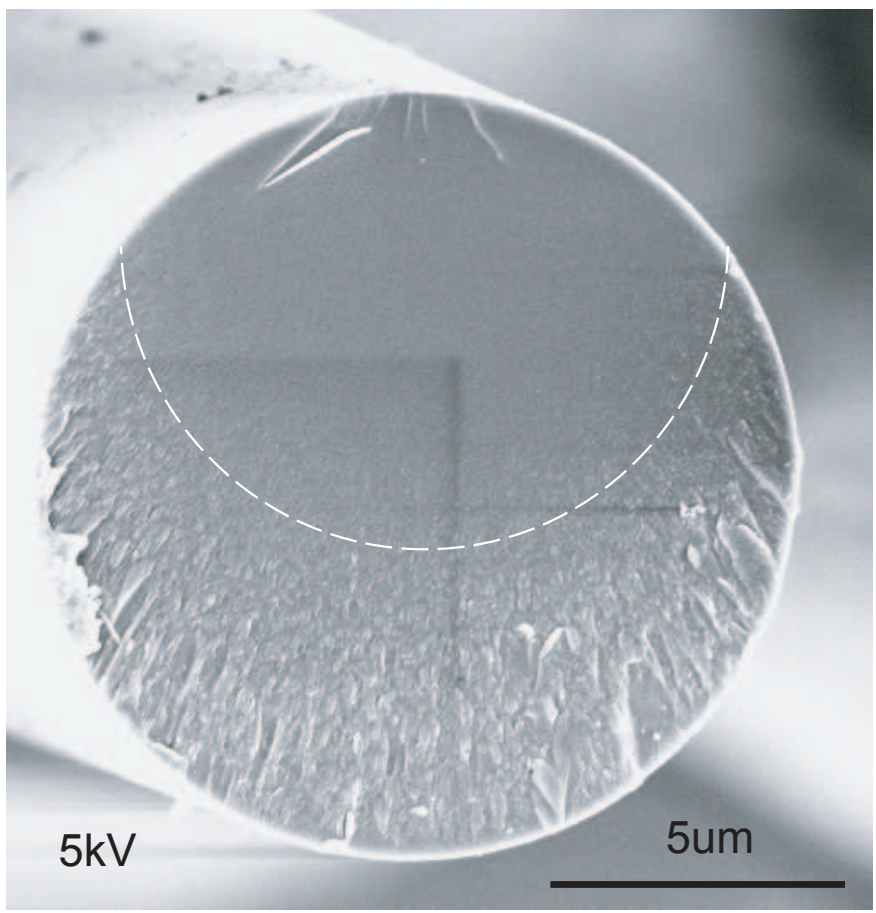


Figure $7 \mathrm{c}$

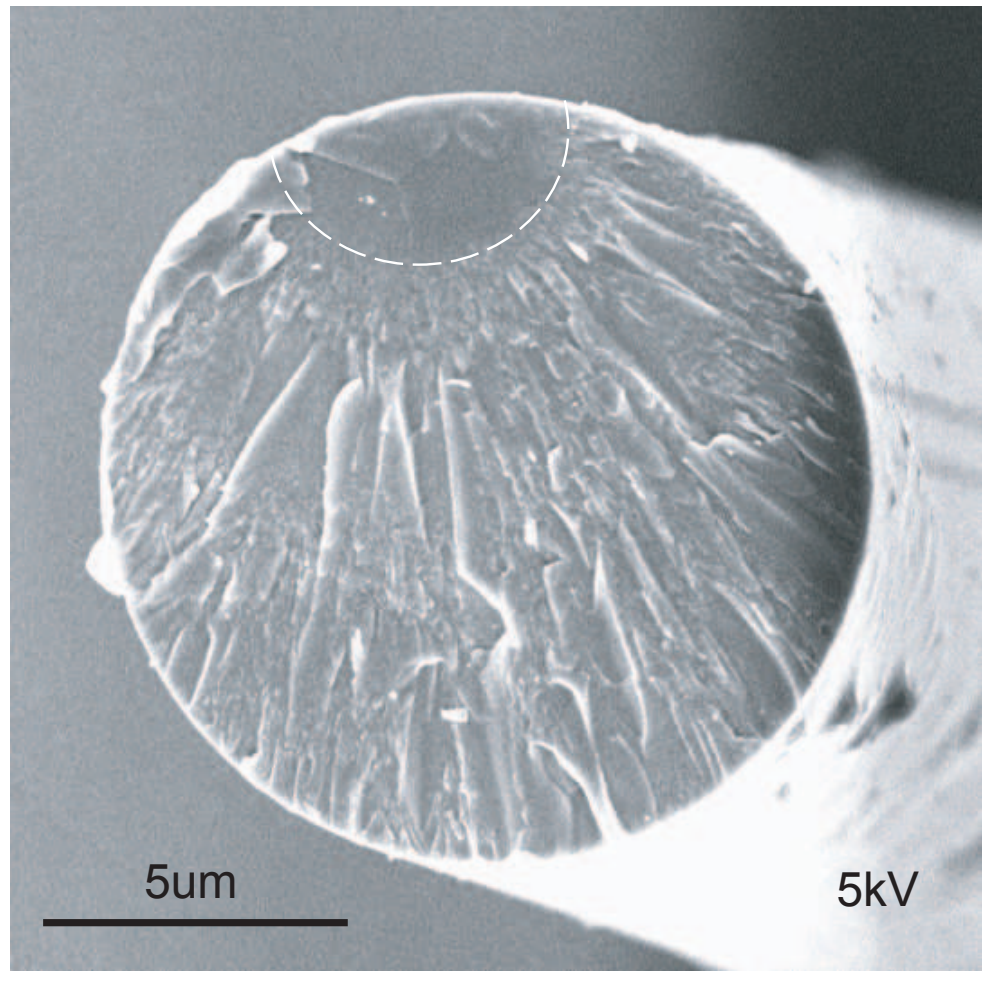

Figure $7 d$

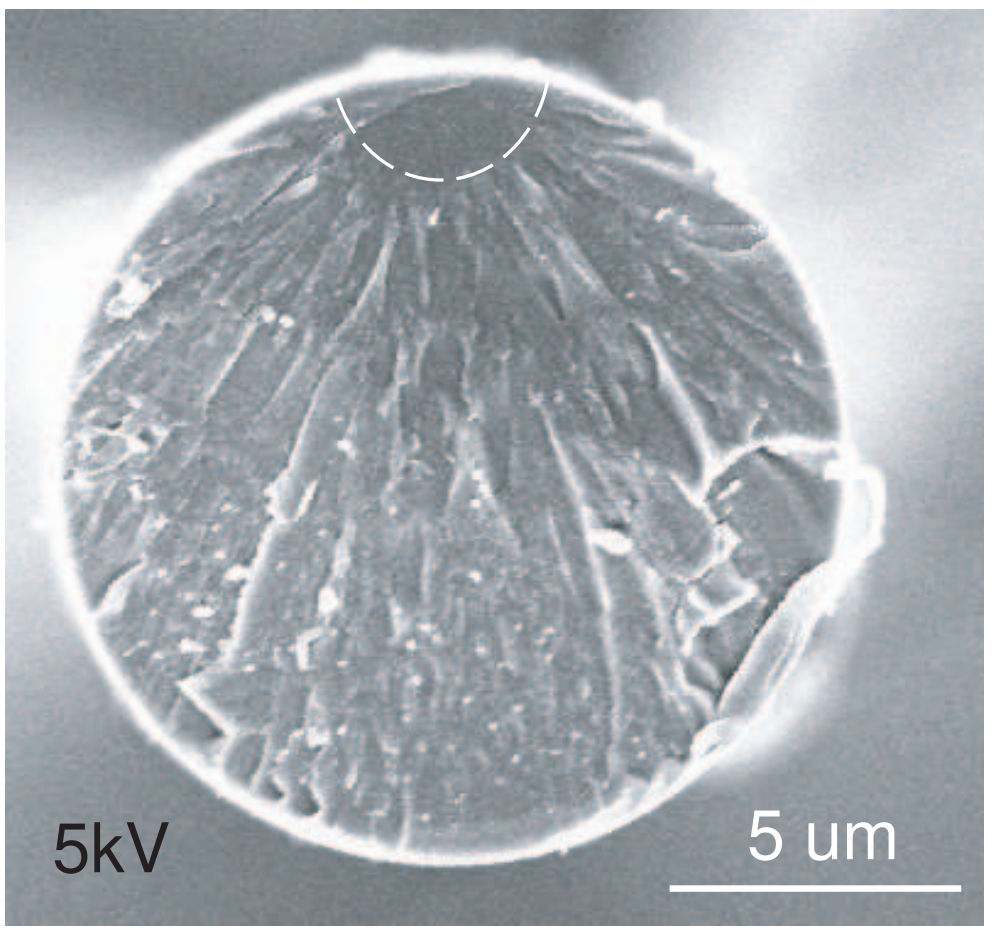


Figure 8

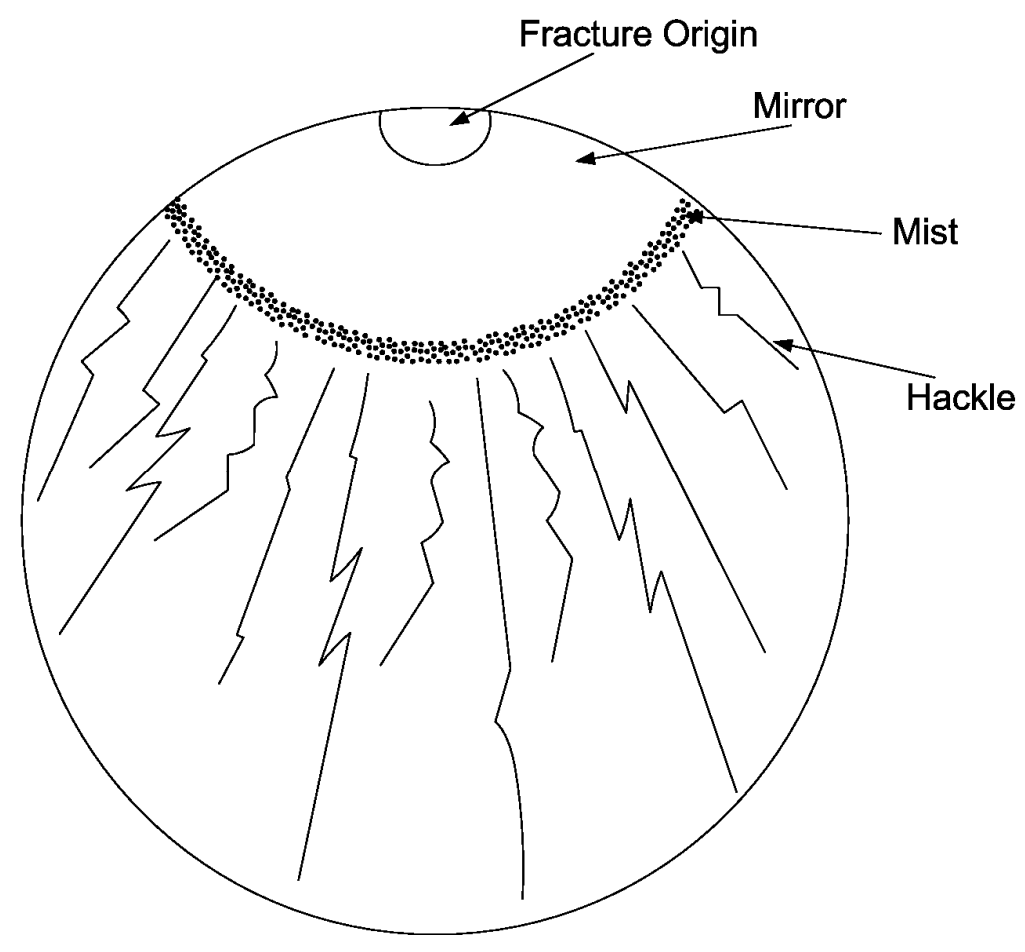


Figure 9

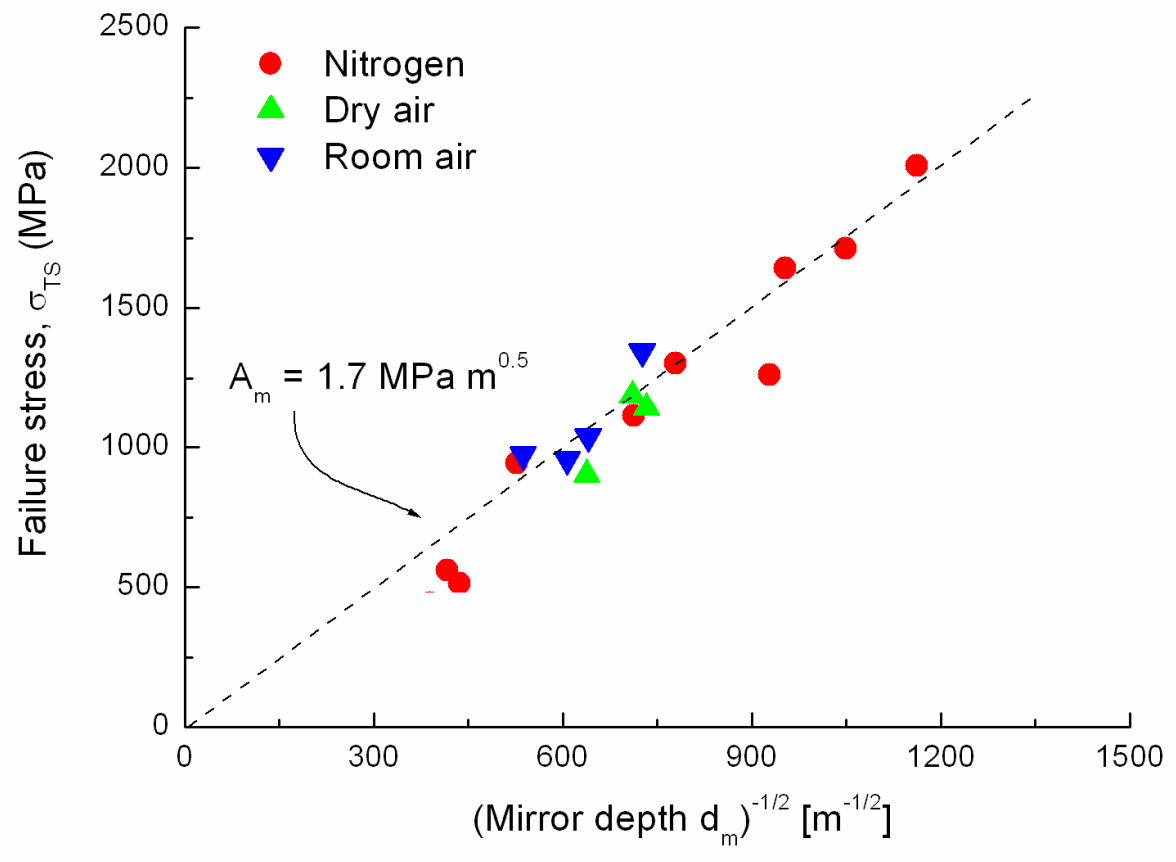


Figure 10

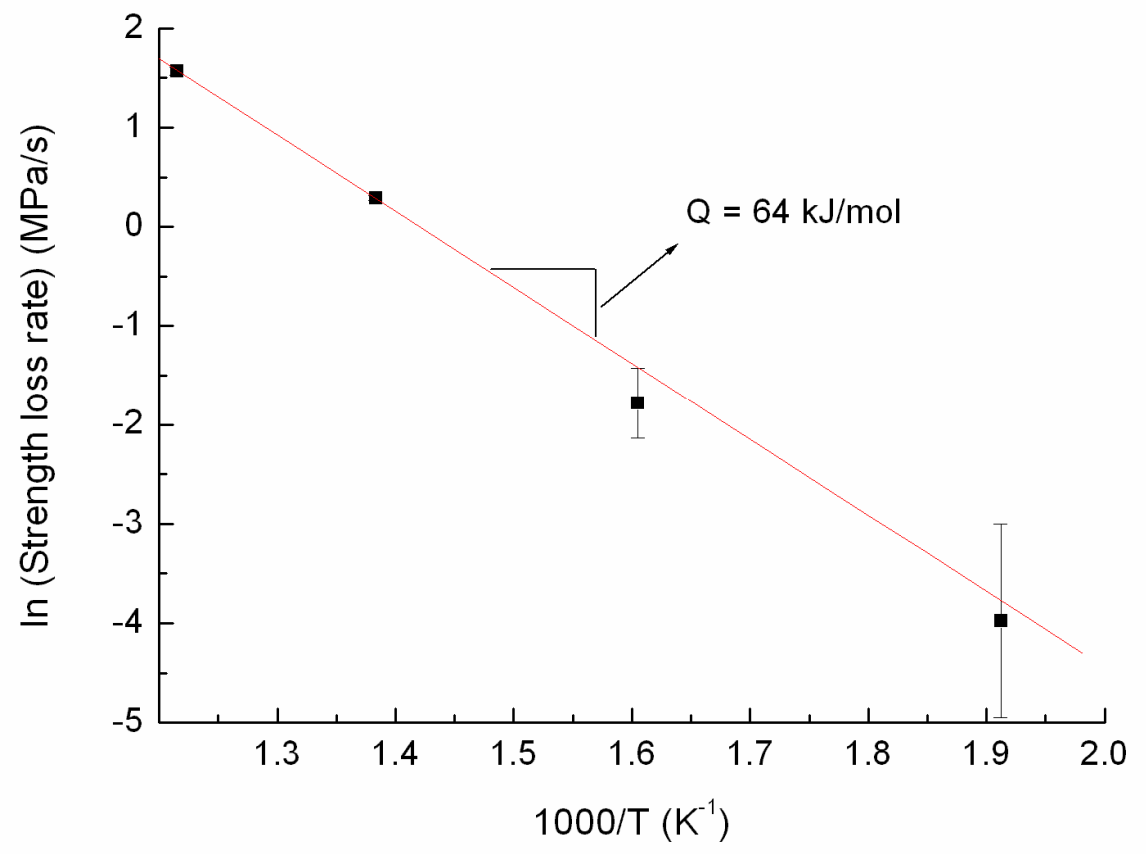


Figure 11

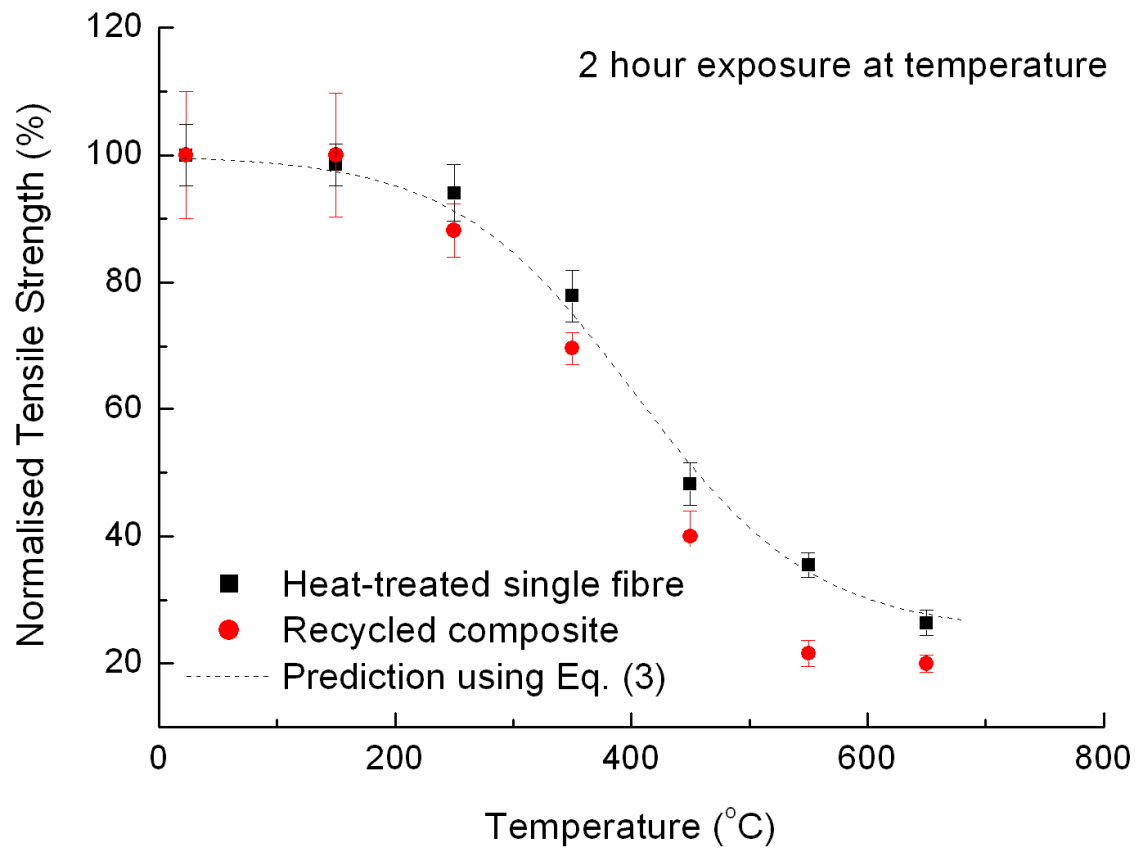

